DOI: $\underline{10.17805 / g g z .2019 .5 .3}$

\title{
Императив моральной ответственности Г. Йонаса как нравственный ответ прошлому за будущее*
}

\author{
И. А. Авдеева
}

Московский государственный университет им. М. В. Ломоносова;

Томский государственный университет

В статье рассматриваются основные моменты концепџии ответственности Ганса Йонаса в аспекте ее императивного содержсания как содержания универсального и всеобщего принципа, полагающего ответственность базовой этической категорией для новой этики. Принцип ответственности представлен как один из вариантов переосмысления традиционной для этики категории ответственности в субъект-субъектных отношениях. Подобное переосмысление было вызвано потребностью выработки новой этики в силу необходимости этического анализа негативного опыта прошлого и созданием ориентиров для настоящего с иелью сохранения будущего. Это происходило вместе с переосмыслением места субъекта и объекта ответственности применительно к действию принципа ответственности и определению временных грании ответственности.

Кониепиия ответственности у Г. Йонаса представлена как неоднозначная, комплементарная, что отражено в содержании императива, предлагаемого философом. Принции ответственности утверждается не просто как универсальный, но как всеобщий и глобальный, категорический в своей безусловной необходимости, ориентированный на оценку последствий деятельности. Однако категоричность не снимается гипотетичностью, а значимость индивидуального действия отнюдь не обесиенивается значимостью коллективной иели. Таким образом, эта концепция стала яркой попыткой создания новой этики перед лицом новых технологических угроз и основанием для построения этического отночения $\kappa$ сочиальнополитическим практикам, выступая в качестве нового универсального подхода наряду с другими концепциями ответственности, выработанными также на основе оценки прошлого опыта с целью предупреждения негативных последствий в будущем и поиском ответов на вызовы новой техногенной иуивилизации.

\footnotetext{
* Исследование выполнено за счет гранта Российского научного фонда (проект №19-1800421).

The study was carried out with financial support from the Russian Science Foundation (project No. 19-18-00421).
} 
Ключевые слова: этика; ответственность; императив; технологические вызовы; глобализация; Ганс Йонас

\title{
H. Jonas's Imperative of Moral Responsibility as an Ethical Answer to the Past for the Future
}

\author{
I. A. Avdeeva
}

Lomonosov Moscow State University; Tomsk State University

The article discusses the main points of the concept of responsibility proposed by Hans Jonas in the aspect of its imperative content as the content of a universal and general principle, which considers responsibility as the basic ethical category for a new ethics. The principle of responsibility is presented as one of the options for rethinking the traditional category of responsibility for ethics in subject-subject relations. This rethinking was caused by the need to develop a new ethics due to the necessity for an ethical analysis of the negative experiences of the past and the creation of guidelines for the present in order to preserve the future. This was happening along with the reinterpretation of the place of the subject and object of responsibility in relation to the operation of the principle of responsibility and determination of a timeframe of responsibility.

The concept of responsibility in H. Jonas's works is presented as ambiguous, complementary, what is reflected in the content of the imperative proposed by the philosopher.

The principle of responsibility is affirmed not just as universal, but as general and global, categorical in its absolute indispensability, oriented to evaluation of the consequences of activity. Nonetheless, categoricality is not removed by the hypothetical character, and the significance of individual action is not devalued by the relevance of collective goal. Nevertheless, this concept was a vivid attempt to create a new ethics in the face of new technological threats and the basis for building an ethical attitude to sociopolitical practices as a universal approach along with other concepts of responsibility developed on the basis of past experience in order to prevent negative consequences in the future in connection with the search for answers to the challenges of a new technogenic civilization.

Keywords: ethics; responsibility; imperative; technological challenges; globalization; Hans Jonas

\section{ВВЕДЕНИЕ}

Социальный опыт последнего столетия поставил перед философией ряд таких глобальных вопросов, которые с необходимостью привели к их этическому осмыслению на протяжении второй половины XX в. Революции, лагеря, войны и глобальные проблемы - тот негативный опыт, который с 
неизбежностью поставил перед этикой задачу поиска новых позитивных императивов, способных на основе этого опыта найти пути выхода из создавшейся критической ситуации в области прежних моральных установок и ориентиров. Переосмысление исторического опыта привело к кризису многих этических установок, а ряд этических идей получили развитие в направлении расширения их универсальности, с одной стороны, а с другой — их практической определенности и применимости. Так, в частности, идея ответственности, имевшая ранее определенную парадигму смысловых связей с категориями свободы, вины человека за свои поступки, индивидуального произволения и др., начинает выходить за рамки этой классической парадигмы и приобретать значения социальной, коллективной, затем всеобщей, глобальной, исторической ответственности, придавая универсальности этой категории не только теоретический, но и практический смысл.

Теоретическая конкретизация степени и характера устанавливаемой всеобщности ответственности проявляла себя во взглядах современных философов по-разному, но с общей тенденцией - усиления значимости индивидуальной ответственности за счет расширения ее социального значимого характера и коллективного значения в силу пережитого негативного исторического опыта. Особенностью такого подхода становится тот факт, что действующий субъект, являясь моральным субъектом, должен стремиться к созданию императивности нового типа - не всеобщего надындивидуального закона для любого действия (например, действия во имя долга, высшей цели или ради добродетели как универсального объекта), а каждого конкретного действия как индивидуального закона и образца для действия по отношению к универсальному субъекту - каждому человеку в отдельности и ко всему человечеству в целом. По этому пути пошли Х. Арендт, Э. Левинас, Г. Зиммель, Ф. Полак и др. В этом же ключе рассуждал и Ганс Йонас, основой для философской концепции которого также стал исторический опыт пережитого. Он стал одним из авторов «инклюзии» этики в общественно-политический дискурс в книге «Принцип ответственности. Опыт этики для технологической цивилизации» (Jonas, 1979; в рус. переводе: Йонас, 2004). «Окончательно освобожденный Прометей, которому наука дала невиданные силы, а экономика - неослабевающий стимул, призывает к этике, которая добровольными узами сдержит его власть» (Jonas, 1987: 7; цит. по: Гаджикурбанова, 2003: 162) — этим лозунгом, достойным времен Великой французской революции, Г. Йонас начинает свой труд.

Отказываясь от «традиционной» этики, Йонас попытался обосновать необходимость «новой» этики, востребованной новой же технологической ситуацией: «Ни одна предшествующая этика не научит нас нормам добра и зла, которые вместили бы совершенно новые модальности власти и ее воз- 
можных творений. Целина коллективного праксиса, на которую мы вступаем с высокими технологиями, является для этической теории еще ничейной землей» (Jonas, 1987: 7; цит. по: Гаджикурбанова, 2003: 162).

Эту «целину» Г. Йонас рисует яркими красками: грядущие изменения природы вкупе с грядущими изменениями природы человека, следствием которых может стать гибель обоих, осложненные необходимостью учета будущих последствий сегодняшней деятельности... По его мнению, складывающаяся ситуация заставляет вновь обратиться к принципу ответственности как основанию новой этики. Подобное толкование ответственности в истории этических учений открытием назвать трудно, однако принципиальной новизной стало расширение границы действия этого принципа в пространстве и времени, которое включило социум и природу, настоящее и будущее. Этот шаг придает этике Йонаса практически вселенские размеры, поскольку у нас есть «долг по отношению к Dasein будущего человечества» и «по отношению к его Sosein» (Jonas, 1987; 145; цит. по: Гаджикурбанова, 2003: 170).

Как уже было отмечено, современная цивилизация в опасениях за собственное будущее формирует четко ощущаемую потребность в новой этике, что объясняется Г. Йонасом принципиальными трансформациями в отношении человечества к собственному будущему в настоящее время (Резвых, 2004: Электронный ресурс). На основании реализовавшихся самых печальных сценариев исторического развития человечество перестало строить иллюзии относительно самого себя. В продолжение этой тенденции изменения морального сознания первоочередной задачей становится размышление над новыми вызовами, среди которых первое место занимают технологические изменения, поскольку до сегодняшнего момента «ни одна из цивилизаций прошлого не располагала техническими возможностями, ставящими под угрозу существование человечества как такового» (там же). Более того, «никогда прежде человеческие действия не имели столь долгосрочных и столь глобальных последствий» (там же). Таким образом, в моральном сознании актуализируется значимость моральной оценки как таковой. И речь идет, в первую очередь, о «моральной оценке последствий собственных поступков», в которых «мы уже не можем руководствоваться только ответственностью перед современниками, но должны принимать во внимание и ответственность» перед всем человечеством - прошлым, настоящим и будущим (там же).

\section{СУБЪЕКТ И ОБЪЕКТ В ФИЛОСОФИИ ОТВЕТСТВЕННОСТИ Г. ЙОНАСА}

Для этой новой парадигмы ответственности характерно расширение как субъекта, так и объекта ответственности - за все, на всех вместе и на 
каждого в отдельности, когда субъект и объект поступка не просто совпадают, но приобретают всеобщий смысл индивидуального выбора как всеобщего выбора, распространяемого на все человечество. В антропоцентричной традиционной этике этическая значимость устойчиво закреплялась за отношениями человека с человеком. Прошлое же оставалось вне сферы этической значимости, так как уже находилось вне сферы нашего влияния. Однако Г. Йонас расширяет границы нравственной вселенной, делая не только настоящее, но и прошлое объектом ответственности. Нравственная вселенная, как называет подобную парадигму мышления об ответственности сам философ, состоит уже не только из современников, выходит за рамки пространственных горизонтов и начинает выстраивают временные горизонты.

Опираясь на анализ социально-исторических трансформаций, приведших к утверждению принципа ответственности, Г. Йонас отмечает изменение субъекта в процессе этих трансформаций, что ведет и к изменению вменения ответственности. Отправным моментом философского анализа отмеченных трансформаций становится развитие технологий, что, с одной стороны, усиливает веру человека в свое могущество, а, с другой стороны, в увлеченности средствами достижения могущества человек умаляет понятие о самом себе и своем бытии. Более того, он производит не только то, что он способен произвести, но и то, что подготовит новые изобретения в будущем и подготовит это будущее. В связи с этим актуализируется коллективный деятель, на первый план выходит совокупность индивидуальных действий, объединенных одним принципом и задачей, а ответственность за действие распространяется на сферу неопределенного будущего даже более, чем на временное пространство, непосредственно окружающее конкретное действие (Коломак А., Коломак Н., 2008: 121). В частности, Природа, по Йонасу, является предметом человеческой ответственности, как в целом, так и в частности. Кумулятивный эффект (как отрицательный, так и положительный, этический) есть у наших единичных поступков. С одной стороны, в конструировании объекта ответственности в рамках новой этической парадигмы, о которой говорит Йонас, знание относительно происходящего является «настоятельнейшей» обязанностью, чтобы исключить прежние разговоры о том, что невозможно предвидеть отдаленные последствия наших поступков, которые перестают быть аргументом в пользу снятия ответственности с единичных поступков. С другой стороны, именно с акцентирования на этическом значении пережитого, через переживание прошлого мы также приходим к необходимости ответственности как всеобщего принципа. Это пережитое прошлое становится в первую очередь объектом и основанием для необходимости разговора об ответственности. Переживание прошлого связано с включением субъекта в переосмысление не только прошлого, но и, через открытие про- 
шлого, открытие самого себя. Прошлое начинает разговор об ответственности и о самом человеке как субъекте ответственности. Прошлое - источник знаний человека о самом себе и базис для вменения ему ответственности. В свою очередь временной ракурс возникновения дискурса об ответственности на основе прошлого приводит к конструированию этического вектора ответственности в контексте будущего как объекта ответственности. Масштабность объекта с неизбежностью влечет за собой и изменение субъекта. В этический дискурс входит коллективный субъект ответственности. Примечателен тот факт, что эпоха тотальных технологических изменений, имеющая место сегодня, носит не просто глобальный, масштабный, кумулятивный и необратимый характер, но меняет значение субъекта. Глобальный характер изменений приводит к пониманию глобального характера действий субъекта, осмысляемого как субъект масштабного и коллективного действия: «Субъект ответственности становится коллективным» также по причине того, что человечество стоит перед необходимостью взятия на себя ответственности за результаты совместной деятельности, имеющей общие последствия, которые угрожают стать негативными и необратимыми (Ручкина, 2008: 311).

Однако это отнюдь не снимает важности индивидуальной ответственности, а лишь подчеркивает ее также масштабный характер и глобальную важность человеческой ответственности в каждом отдельном случае за результат того, что мы хотим получить в будущем. При таком подходе изменение положения субъекта в «новом» мире характеризуется еще и трансформацией его онтологического статуса присутствия как данности в присутствие как нравственной обязанности, предполагающей включенность субъекта в универсум нравственности для обеспечения в будущем наличия в материальном мире. Присутствие субъекта есть тезис, их которого выводятся все последующие этические идеи Г. Йонаса об обязательных и необходимых принципах морального поведения.

\section{ИМПЕРАТИВНОЕ СОДЕРЖАНИЕ ОТВЕТСТВЕННОСТИ}

Обращаясь к конкретному историческому опыту Г. Йонас приходит к той мысли, что принцип ответственности как надысторический принцип также должен быть направлен на будущее. Ради благополучия будущих поколений на основании идеи ответственности создается новая императивность. Эта императивность необходима как базис для перехода к новым мировоззренческим основаниям жизни, ориентированной на такое будущее, где негативное прошлое не должно повториться. Будущее становится объектом исторической ответственности для действий в настоящем. Таким образом, наша главная ответственность - это наша ответственность за совершенные 
и совершаемые поступки, которые конструируют будущее, на которое мы можем (в отличие от прошлого) оказать влияние. Это требует императивов нового рода, расширяя сферу этического на все прочие сферы человеческой деятельности. И, прежде всего, этическое становится мерилом общественнополитической формы человеческих отношений, поскольку «никогда прежде общественная жизнь не имела дела с вопросами такой объемности и столь отдаленными предвосхищениями. ...изменившаяся природа человеческой деятельности меняет фундаментальную сущность политики» (Йонас, 1999: 16)., что требует нового знаменателя этой деятельности. Этим знаменателем становится у Йонаса новая императивность.

Уделяя особое внимание критике традиционной этики в свете изменившейся деятельности, философ предполагает, что Благо или Зло становятся объектами отдаленного планирования, что вызывает необходимость предвидения последствий наших этических решений, вменяемость наших действий, контроль над ситуацией и умение видеть отдаленные цели с точки зрения ответственности. Просто знание и воление в новой всеобщей этической универсальности уступают место особой ответственности, так как «никакой предыдущей этике не приходилось принимать в расчет глобальные условия человеческой жизни и отдаленное будущее, даже само существование человеческого рода» (Йонас, 2004: 53). Отмечая тот факт, что категорический императив И. Канта уже не удовлетворяет этическим запросам новой эпохи, Йонас формулирует свой собственный императив, для которого необходимы как личные, так и коллективные усилия с позиций ответственности.

Логическим следствием всех метафизических конструкций относительно возможностей новой этики стал сложно составленный императив:

- «Поступай так, чтобы последствия твоего действия были совместимы с непрерывностью подлинной человеческой жизни на земле».

- «Включай в свой нынешний выбор будущую совокупность людей в качестве предмета твоего воления».

- «Поступай так, чтобы последствия твоих действий не были разрушительны для будущей возможности жизни как таковой».

- «Не подвергай опасности условия неограниченного дальнейшего существования человечества на земле» (Jonas, 1987: 36; цит. по: Гаджикурбанова, 2003: 170-171).

Новый императив, соответствующий новым типам человеческих действий и адресованный новым типам агентов действия, должен, по утверждению Йонаса, быть построен так, чтобы согласно этому императиву, мы могли бы рисковать своей собственной жизнью, но не жизнью человечества. Из этого, принимая во внимание существенную зависимость будущего от сегодняшней технологической практики, вытекает необходимость культивирова- 
ния известной осторожности в принятии решений за безопасное будущее вследствие уроков прошлого, которое не единожды показывало нам, что необходимо заботиться о безопасности человечества как специфической этической обязанности. Вопрос же о том, способен ли скованный страхом Прометей сделать хоть что-либо в таких условиях, остается за скобками, ибо в полной мере последствия поступков предугадать достаточно трудно. Впрочем, можно предположить, какая была бы любопытная история у человечества, если бы этика ответственности существовала в эпоху Великих географических открытий.

В целом же императив Г. Йонаса при всей его «деонтологической безукоризненности» и нравственной «идеальности» выстроен на довольно шатких основаниях — возможности приемлемого точного прогнозирования последствий тех или иных действий и наличия времени для подготовки опять же более или менее точных предсказаний. А вот их-то как раз и нет - недостатки футурологии, балансирующей между наукой и фантастикой, известны достаточно хорошо и пока неустранимы, а ускорение как искусственных, так и естественных процессов, все быстрее вводящее глобальный социум в состояние кризиса, - практически аксиома, уже не требующая доказательств. И поэтому императив Йонаса может быть со всей ответственностью применен и к его этике. Столь же шатким выглядит и страх в качестве основания следования долгу - при всей его безусловной силе, это понятие вряд ли может расцениваться как плодотворное: как говорится, на штыки можно опираться, но на них нельзя сидеть. Что же касается критики морального императива в отсутствии его убедительной философской обоснованности, то ответ можно найти в словах самого философа: «Однако новый императив говорит именно о том, что мы вправе рисковать собственной жизнью, но не жизнью человечества, что хотя Ахилл был в полном праве предпочесть краткую насыщенную славными подвигами жизнь - долгой жизни в бесславной безопасности (при подразумеваемом условии существования будущих поколений, которые смогут рассказывать о его деяниях), у нас нет права избирать небытие будущих поколений для того, чтобы могло существовать поколение нынешнее, или хотя бы даже рисковать их бытием для нынешнего. Нелегко, а без религии, быть может, и вовсе невозможно дать теоретическое обоснование того, почему у нас нет такого права, почему мы, напротив того, имеем обязанность перед тем, чего еще вовсе нет и что “как таковое” быть нисколько не обязано, и уж во всяком случае, как несуществующее, никак не в состоянии претендовать на бытие» (Йонас, 2004: 58-59; курсив источника. И. A.). 


\section{ПРИНЦИП ОТВЕТСТВЕННОСТИ КАК ОСНОВАНИЕ НОВОЙ ЭТИКИ ОТНОШЕНИЯ ВО ВРЕМЕННОМ КОНТИНУУМЕ «ПРОШЛОЕ - БУДУЩЕЕ»}

Тем не менее, вряд ли этика ответственности приобрела бы такую популярность, если бы не страх, как основной принцип ответственности. Сам же указанный принцип лишь обозначает «скромную задачу... которая заповедует страх и заповедь: сохранить человеку, при сохраняющейся двойственности его свободы... неприкосновенность его мира и его сущности против угрозы со стороны собственной власти» (Apel, 1988: 9; цит. по: Назарчук, 2002: 41) В качестве регулятивного принципа страх для традиционной этики весьма необычен, но, по мнению Г. Йонаса, для этики технологической цивилизации, стоящей на пороге гибели, вполне приемлем, поскольку может стать мощным стимулом для тщательной предварительной оценки результатов тех или иных действий, так как он исходит из преимущества неблагоприятного прогноза перед благоприятным. Речь идет не столько о пророчестве бедствий, сколько о включенности в саму этическую теорию элемента неуверенности как повода «для нового фундаментального положения, которое, в свою очередь, может сделаться практическим предписанием. Это предписание, сформулированное в примитивной форме, велит больше прислушиваться к пророчествам бедствий, чем к пророчествам благоденствия» (Йонас, 2004: 86; курсив источника. - И. А.) и избавляет нас от психологической опасности обетованного благополучия, указывая на несовершенство бытия, напоминая о двузначности человеческого существования.

Другой специфической чертой принципа ответственности является тот факт, что различая ответственность естественную и договорную, проводя различия между этими двумя видами ответственности, Г. Йонас говорит о том, что мы знаем только один вид естественной (природной ответственности) - родительская ответственность. Все же прочие социальные конструкты являются видом договорной ответственности. Однако безусловность и безотзывность той ответственности, которую он возводит в принцип, приближает ее именно к ответственности естественной: «Однако в отношении этого, вечно необеспеченного в своем существовании, целиком и полностью зависящего от нас блага ответственность настолько же безусловна и безотзывна, как только может быть любая ответственность, установленная природой - если только она уже природной не является. Так что если чиновникпредатель может быть непосредственно обвинен лишь в нарушении долга, то опосредованным образом безответственен и он» (там же: 176).

Новая этика ответственности Г. Йонаса может быть рассмотрена и как столь же любопытная попытка восстановить главное преимущество этики религиозной (поступая нравственно здесь и сейчас, человек получает ком- 
пенсацию после смерти), утраченное в процессе секуляризации, - поступая нравственно здесь и сейчас, человек получит компенсацию в виде выживания всего человечества. Как представляется, этот ход достаточно эффективен как в практическом - исследования подтверждают готовность людей к самопожертвованию во имя, по крайней мере, родственников, так и в теоретическом плане - конечность обещаний рая на земле всегда была минусом глобальных идеологий. В этом контексте неслучайной кажется и симпатия Йонаса к коммунизму на фоне общего его неприятия.

Несмотря на то, что философскую позицию Г. Йонаса часто связывают с экспликацией теологических оснований применительно к новой этике техногенной эпохи, сам философ не позволяет забывать об экзистенциальном измерении человеческого бытия, обращая постоянное внимание читателя на «свободное деяние» человека как «исключительно свое собственное дерзкое нравственное предприятие». Именно в такой ситуации «человек высказывает претензию на ничейную до того ответственность и, разумеется, после этого оказывается под властью ее претензий на себя. <..> Высшая и наиболее самонадеянная свобода самости приводит к наиболее повелительному... долженствованию» (там же: 179). Однако одновременно с этим императив ответственного поведения предполагает практическое воплощение в общественно-политической деятельности в силу причинно-следственного измерения последней, к которому собственно и мог бы быть применим новый моральный императив в отличие от кантовского императива, обращенного к человеку, как считал сам Йонас. Более того, при детальном рассмотрении выше упомянутой «деонтологической безукоризненности» нового императива предполагается внимание к реальным последствиям, что предполагает создание объективной ответственности в отличие от субъективного самоопределения. Таким образом, соединение экзистенциального и социальнополитического, личного и коллективного, деонтологического и телеологического создают достаточно конфликтное поле содержательной специфики принципа ответственности как универсального и одновременного конкретнопрактического принципа деятельности. Но для философа этика ответственности - это готовность жить с конфликтом, т. е. с другими точками зрения, которые могут не совпадать по самым ключевым вопросам, но при этом они будут признаваемы в качестве ценностных позиций. Это готовность согласиться с утверждением, что невозможно рационально и исчерпывающе обосновать единую верную систему этики, что участь морального субъекта с необходимостью включает участие в безнадежной борьбе за идеал, где конкретный субъект занимает центральное место, так как ему открывается то, что не может быть делегируемо никому другому кроме него самого. Однако мораль предполагает социальность, иначе это ведет к замкнутости на себе, а 
также к равнодушию и безответственности. Отсюда следует готовность к борьбе за свой идеал без возможности сделать его универсальным. При другом подходе не менее, а, возможно, гораздо более убедительном из-за произошедших катастрофических изменений, насилие может стать персоной non grata в той же самой этике ответственности. В попытке избежать повторения негативного опыта прошлого, Йонас переносит фокус главной ценности с нации на человечество в целом, и тогда уже интересы нации становятся актуальны ровно настолько, насколько они не противоречат интересам человечества, а прежде всего возможности его выживания. Он убежден, что государственный человек не должен для спасения своей нации использовать средство, которое может уничтожить человечество. В подобных построениях ответственность состоит не в поддержке своей нации даже вопреки несправедливостям, но исходит в первую очередь из высшей ценности конкретного человека и человечества в целом.

Г. Йонас не был одинок в стремлении распространить действие этики за пределы социальных отношений и отношений «здесь и сейчас», отвечая на глобальные вызовы, формирующиеся перед глобальным же человечеством. Идея, можно сказать, «носилась в воздухе», наполненном апокалиптическими прогнозами, предсказывающими скорый экологический кризис. В рассуждениях об ответственности ряд философов (например, П. Рикер) обращают внимание на контекстуальных употреблениях термина «ответственность» через связку с категорией обязательства. Ответственным объявляется тот, кто подчиняется этим этическим, т. е. добровольно взятым на себя обязательствам. Если убрать это личное обязательство за будущее всего человечества, отталкиваясь от опыта прошлого, то принцип ответственности теряет свое этическое (без вознаграждения, без наказания и санкций) значение. Мы принимаем на себя обязательство за саму идею человека, поскольку это в наших силах, и главная наша ответственность ложится за самих себя именно на нас перед этой идеей человека, необходимой для присутствия ее воплощений в мире. Мы носители и живое воплощение этой идеи. Это онтологическая идея, которая делает наше обязательство таковым. Никакое средство не существует дольше имманентной цели, поэтому надо выбирать человечество в индивидуальном поступке - вот основной пафос морального императива.

В таком же значении существует ответственность и у Г. Йонаса, возводящего ее в принцип новой этики.

\section{ЗАКЛЮЧЕНИЕ}

В современных дискуссиях озабоченности этическим опытом прошлого все чаще звучат лейтмотивом всех споров разговоры о кризисе социальности, идеи приоритета моральности над социальностью. В этих дискуссиях 
установление тесной взаимосвязи социальности и моральности в аспекте доминирования социальной реальности привело к установлению четкой привязки моральности к социальным практикам, без которых мораль и моральность не мыслятся в принципе. Однако опыт прошлого говорит нам о дискредитации данной детерминации. В этой связи автономия моральности становится новой отправной точкой в коррекции той социальности, которая себя упорно дискредитировала на протяжении всей первой половины XX в. Наделяя моральным содержанием весь исторический опыт предыдущего столетия, в поисках путей преодоления кризиса многих мировоззренческих установок мы обращаемся к идеям Г. Йонаса как попыткам реабилитировать универсальность этического подхода к социальным и политическим практикам. Идея ответственности в переосмыслении всего того, что предлагает нам для анализа новейшая история, становится тем мостом, который из социальной реальности ведет к мосту в реальность морального как всеобщего. Ибо без подобной отсылки с целью осмысления исторического опыта дальнейший путь социально-исторической и культурного движения рискует остаться в тупиковом положении. Принципа взаимности в этике будущего нет, как нет и баланса. Есть только страх, надежда и ответственность: «Может пройти даже неблагодарность по отношению к тому, что было в прошлом, ибо и в самом деле исторический баланс представляет собой что угодно, но не однозначную величину, и, возможно, вина всегда перевешивает там справедливость. Но что в отрицании самозначимого настоящего всех вообще “предшественников” действительно пагубно, так это возникающее отсюда убийственное соотношение средств и целей, способное изничтожить самую возвышенную цель», — пишет Йонас (Йонас, 2004: 360). Таким образом, только «этика будущего, обладающая дальностью предвидения, протяженностью принимаемой ответственности во времени, обширностью предмета (все будущее человечество) и глубиной интересов (вся в целом будущая человеческая сущность), а, кроме того, как мы можем уже добавить, этика, всерьез принимающая техническую мощь» (там же: 66) и отказавшаяся от утопизма в оценке ее последствий, может стать ответом прошлому европейской цивилизации. В ответственности за будущее не остается сфер нравственно безразличного перед лицом таких величин, надежность которых определяется не только нашими представлениями об идеальном, но и надежностью научных проекций, снабжающих его прагматическим материалом. Степень этой надежности обеспечивается как надежностью идеального представления и фундаментального морального принципа, так и надежностью проекций нежелательных проекций будущего на основе прошлого. 


\section{СПИСОК ЛИТЕРАТУРЫ}

Гаджикурбанова, П. А. (2003) Страх и ответственность: этика технологической цивилизации Ганса Йонаса // Этическая мысль. Вып. 4. М. : ИФ PAH. 205 c. С. 161-178.

Йонас, Г. (1999) Изменившийся характер человеческой деятельности // Человек. № 2. С. 5-19.

Йонас, Г. (2004) Принцип ответственности. Опыт этики для технологической цивилизации / пер. с нем., предисл., прим. И. И. Маханькова. М. : Айрис-пресс. $480 \mathrm{c}$.

Коломак, А. И., Коломак, Н. С. (2008) Этика ответственности к окружающей нас природе // Вестник Северо-Кавказского государственного технического университета. № 2 (15). С. 117-121.

Назарчук, А. В. (2002) Этика глобализирующегося общества: тенденции и проблемы глобализации в свете социально-этической концепции немецкого философа К.-О. Апеля. М. : Директ-Медиа. 809 с.

Резвых, П. (2004) Оптимистическая антиутопия [Электронный ресурс] // Независимая газета. 5 августа. URL: http://www.ng.ru/koncep/2004-08-05/6 ethics.html [архивировано в WaybackMachine] (дата обращения: 19.11.2019).

Ручкина, М. В. (2008) Ответственность как способ самозащиты субъекта риска // Известия Российского государственного педагогического университета им. А. И. Герцена. № 82-1. С. 309-315.

Apel, K.-O. (1988) Diskurs und Verantwortung : das Problem des Übergangs zur postkonventionellen Moral. Frankfurt am Main : Suhrkamp. 487 S.

Jonas, H. (1979) Das Prinzip Verantwortung: Versuch einer Ethik für die technologische Zivilisation. Frankfurt am Main : Insel-Verlag. 423 S. (Suhrkamp taschenbuch. Vol. 1085).

Jonas, H. (1987) Das Prinzip Verantwortung. Versuch einer Ethik für die technologische Zivilisation. Zürich : Buchclub Ex Libris. 423 S.

Дата поступления: 08.11.2019 г.

\section{REFERENCES}

Gadzhikurbanova, P. A. (2003) Strakh i otvetstvennost': etika tekhnologicheskoi tsivilizatsii Gansa Ionasa [Fear and responsibility: Ethics of the technological civilization of Hans Jonas]. In: Eticheskaya mysl' [Ethical thought], issue 4. Moscow : Institute of Philosophy, RAS. 205 p. Pp. 161-178. (In Russ.).

Jonas, G. (1999) Izmenivshiisia kharakter chelovecheskoi deiatel'nosti [The changed nature of human activity]. Chelovek, no. 2, pp. 5-19. (In Russ.).

Jonas, G. (2004) Printsip otvetstvennosti. Opyt etiki dlia tekhnologicheskoi tsivilizatsii [The principle of responsibility. Experience of ethics for technological 
civilization] / transl. from German, foreword and notes by I. I. Makhankov. Moscow : Airis-press. 480 p. (In Russ.).

Kolomak, A. I. and Kolomak, N. S. (2008) Etika otvetstvennosti k okruzhaiushchei nas prirode [Ethics of responsibility towards nature around us]. Vestnik Severo-Kavkazskogo gosudarstvennogo tekhnicheskogo universiteta, no. 2 (15), pp. 117-121. (In Russ.).

Nazarchuk, A. V. (2002) Etika globaliziruiushchegosia obshchestva: tendentsii i problemy globalizatsii $v$ svete sotsial'no-eticheskoi kontseptsii nemetskogo filosofa K.-O. Apelia [Ethics of globalizing society: Trends and issues of globalization in the light of the social and ethical conception of the German philosopher K.O. Apel]. Moscow : Direkt-Media Publ. 809 p. (In Russ.).

Rezvykh, P. (2004) Optimisticheskaia antiutopiia [Optimistic antiutopia]. Nezavisimaia gazeta, August 5. [online] Available at: http://www.ng.ru/koncep/ 2004-08-05/6_ethics.html [archived in WaybackMachine] (accessed 19.11.2019). (In Russ.).

Ruchkina, M. V. (2008) Otvetstvennost' kak sposob samozashchity sub"ekta riska [Responsibility as a way of risk subject's self-defence]. Izvestiia Rossiiskogo gosudarstvennogo pedagogicheskogo universiteta im. A. I. Gertsena, no. 82-1, pp. 309-315. (In Russ.).

Apel, K.-O. (1988) Diskurs und Verantwortung : das Problem des Übergangs zur postkonventionellen Moral. Frankfurt am Main : Suhrkamp. 487 S. (In Germ.).

Jonas H. (1987) Das Prinzip Verantwortung. Versuch einer Ethik für die technologische Zivilisati Das Prinzip Verantwortung. Versuch einer Ethik für die technologische Zivilisation. Zürich : Buchclub Ex Libris. 423 S. (In Germ.).

Jonas, H. (1979) Das Prinzip Verantwortung: Versuch einer Ethik für die technologische Zivilisation. Frankfurt am Main : Insel-Verlag. 423 S. (Suhrkamp taschenbuch. Vol. 1085). (In Germ.).

Submission date: 08.11.2019.

Авдеева Ирина Александровна - кандидат философских наук, доцент философского факультета МГУ имени М. В. Ломоносова, научный сотрудник философского факультета Томского государственного университета. Адpec: 119234, Россия, г. Москва, Ломоносовский проспект, д. 27, корп. 4. Тел.: +7 (495) 939-20-55. Эл. адрес: avdeeva@rambler.ru 
Avdeeva Irina Aleksandrovna, Candidate of Philosophy, Associate Professor, Faculty of Philosophy, Lomonosov Moscow State University; Researcher, Faculty of Philosophy, Tomsk State University. Postal address: 27, Bldg. 4, Lomonosovskiy Prospekt, 119234 Moscow, Russian Federation. Tel.: +7 (495) 93920-55. E-mail: avdeeva@rambler.ru

Researcher ID: S-4885-2017

SPIN-код РИНЦ: $\underline{\text { 5906-3242 }}$

Для ичитирования:

Авдеева И. А. Императив моральной ответственности Г. Йонаса как нравственный ответ прошлому за будущее [Электронный ресурс] // Горизонты гуманитарного знания. 2019. № 5. C. 47-61. URL: http://journals.mosgu.ru/ ggz/article/view/1102 (дата обращения: дд.мм.гггг). DOI: 10.17805/ggz.2019. $\underline{5.3}$ 